Title:

Instrumentation for High-Efficiency, HighSensitivity Actinide Analysis

Author(s):

Jose Olivares, CST-9

Edwin Chamberlin, CST-11

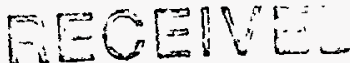

APR i 2 1950

Michael Murrell, CST-7

Michael Kahr, CST-9

Yixiang Duan, CST-9

OSTI

Submitted to:

DOE Office of Scientific and Technical Information (OSTI)

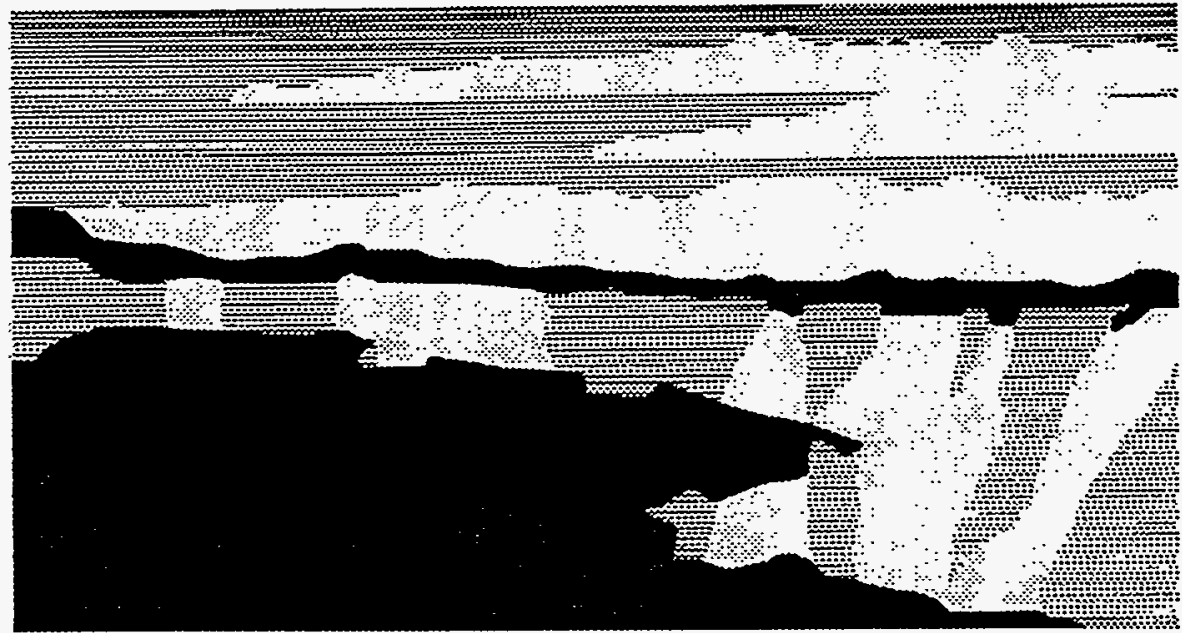

Los Alamos Natlonal Laboratory an affirmative action/equal opportunity employer, is operated by the University of Callomia for the U.S. Department of Energy under contract W-7405-ENG-36. By acceptance of this article, the publisher recognizes that the U.S. Government retains a nonexclusive, royaltyfree license to publish or reproduce the published form of this contribution, or to allow others to do so, for U.S. Government purposes. The Los Alamos Natlonal Laboratory requests that the publlsher identify this article as work performed under the ausplces of the U.S. Department of Energy.

$$
\text { DISTRIQUTTON OF THIS DOCLMENT IS LNLMITED }
$$




\title{
Instrumentation for High-Efficiency, High-Sensitivity Actinide Analysis
}

Jose Olivares*, Edwin Chamberlin, Michael Murrell, Michael Kahr, and Yixiang Duan

\begin{abstract}
This is the final report of a three-year, Laboratory-Directed Research and Development (LDRD) project at the Los Alamos National Laboratory (LANL). We have developed a high-efficiency thermal ionization source that provides one to two orders of magnitude improvement in sample utilization efficiency in comparison with the traditional filament-type ion source currently used in thermal ionization mass spectrometry. This improved sample utilization efficiency results in a proportional increase in sample throughput and proportional decrease in analysis time. Coupling this source with a quadrupole mass spectrometer results in an instrument system for highefficiency actinide analysis and other applications. In addition to its high efficiency, the sample used in this source can be much smaller than that in the previous tube-type sources. The compact structure of the cavity makes it more applicable to any type of mass spectrometer and the whole instrument is small and transportable.
\end{abstract}

\section{Background and Research Objectives}

Thermal ionization mass spectrometry (TIMS) is an analytical tool used extensively in our laboratories to determine both the absolute abundance and the isotopic composition of actinide samples (thorium, uranium, plutonium, americium, neptunium, etc.). TIMS is applied to weapons test diagnostics, geological sciences, and environmental analysis. Although TIMS is a very sensitive analytical technique, sample utilization efficiency is below $0.5 \%$ for the actinides. The project goal was to build a thermal ionization cavity that replaces the conventional ribbon type ion source currently used in TIMS and that can provide up to 150 times higher sample utilization efficiency.

The enhanced capabilities offered by high-efficiency, high-sensitivity analytical measurements of the actinides is clear. There is only one method currently in use that is able to generate thorium ions with percent efficiency for mass spectrometry. This approach utilizes

*Principal investigator, e-mail: olivares@lanl.gov 
secondary ionization mass spectrometry and a $\$ 1 \mathrm{M}$ ion probe [35]. Although interesting and novel, the high cost and complexity of such a system hampers application to routine analysis.

Our thermal ionization cavity for mass spectrometry is based on an existing model used in isotope separators for production of milligram quantities of various isotopes. Basically, isotope separators are multi-million dollar mass spectrometers used for production of high purity isotopes. This ionization technique is 150 times more efficient than the standard ribbon thermal ionization source used on our analytical mass spectrometers for isotopic measurements. This enhancement in ion production is due to the multitude of atomic collisions that occur in the cavity and the formation of a potential well that acts as an ion "trough" [27].

The Laboratory has a long history of success in using the thermal ionization cavity to efficiently ionize refractory samples. Today, rare-earth separation efficiencies $>20 \%$ are typical with an average of $\sim 30 \%$. A feasibility study on one of our isotope separators showed that this ion source can in fact give thorium ion signals $\sim 100$ times more intense than those achieved by conventional thermal ionization mass spectrometers for similar size samples.

The isotope separator thermal ionization cavity source is shown in Fig. 1. It is a variant of the sources described by Beyer et al [11] and Johnson et al [12]. The general configuration of the source has remained unchanged but sample utilization efficiency has improved with increased understanding of the ionization process [26], sample preparation requirements, crucible fabrication techniques, and operational techniques.

Our approach was to scale down this unique LANL capability to our mass spectrometers. This approach allows the timely introduction of a high-efficiency ion source for actinide analysis at a time when the geoscience and environmental communities are trying to solve problems requiring reduced sample sizes. The scientific community will gain from the development of an ion source for use on less expensive, more routine, and widely available mass spectrometers.

\section{Importance to LANL's Science and Technology Base and National R\&D Needs}

The Laboratory currently has projects that make direct use of high precision isotopic analysis of the uranium-disequilibrium decay series. The Laboratory also provides low-level actinide measurements for Rocky Flats and for internal environmental restoration programs. All of these projects can benefit from a technique that improves the efficiency of use of samples and increases the overall sensitivity of measurements by more than an order of magnitude. In addition, the applications of such an ion source extend well beyond the actinide elements to nearly any element with refractory behavior and relatively low first-ionization potential. 
Because of the wide application of such a system, commercialization should be possible and we are working to identify an industrial partner. The Laboratory's continued interest in solving real problems in geochronology, geological risk assessment, environmental migration studies, paleoclimate studies, and weapons diagnostics will provide the impetus for successful implementation of this type of instrumentation development and technology transfer.

\section{Scientific Approach and Results}

TIMS is one of the most powerful techniques used to determine both the absolute value and the relative isotopic abundance of elements [1,2]. Thermal ionization is efficient for elements that contain relatively low or moderate first-ionization energies and with sufficient vapor pressure at the operating temperature. Thermal ionization sources use single, double, and triple ribbon-type filaments for sample vaporization and ionization. The method has been broadly employed in the geochemistry, environmental chemistry, and the study of nuclear materials [3-9]. Although TIMS is a very sensitive technique, sample utilization efficiency is usually limited in the conventional ion sources. For example, the traditional thermal ionization sources usually have sample utilization efficiency of less than $1 \%$ for actinides [10]. Apart from the use of chemical enhancers and modifiers and some improved methods for sample preparation, there has been limited work reported on improvements of the thermal ionization source performance.

In the early 1970 s a new type of thermal ionization source was developed almost simultaneously by Beyer in Dubna [11] and by Johnson at Livermore [12] in which a refractory metal tube with a deep cavity was used to evaporate and ionize the samples. In this way, the thermal temperature of the sources and the atom/surface interactions can be significantly increased, and the sample ionization efficiency was greatly improved. This thermal ionization cavity (TIC) has been developed extensively for applications to large-scale isotope separator projects (ISOL). Consequently, both theoretical and experimental studies were performed on such cavities to better understand the ionization mechanism of the analytes [24-27]. The influence on the ionization efficiency of cavity parameters (e.g., filament work function, source temperature, plasma density, and pressure of the neutral particles) was explored. More recently, Delmore and his co-workers introduced a similar tube-type source for the study of chemical effects of surface ionization, in which the source is used as an ion gun for secondary ionization mass spectrometry [21].

In this report we present a version of the TIC source developed specifically for use in mass spectrometry. The performance of this ion source has been characterized extensively both with the use of an isotope separator and a quadrupole mass spectrometer. A detailed 
description is given of the TIC source for mass spectrometry along with the performance characteristics observed to date.

\subsection{Ion Source Design Features}

Basic Structure. The design of the new ion source has the primary goal of achieving large sample-utilization efficiencies comparable to those achieved by the larger sources used in the ISOL projects. With that goal in mind, the new ion source was designed as shown in Fig. 1. Fig. 1A shows the transverse section view of the ion source coupled to a quadrupole mass spectrometer system. The principle components of the assembly are a) the adapter flange used to accommodate the ion source on the mass spectrometer, b) the sample crucible with a cavity where the sample is loaded, and c) the electron emission filament and shield used to heat the crucible and shield the rest of the ion source from emitted electrons. The ion source can be mounted on an isotope separator or a quadrupole mass spectrometer without modifications. In the current configuration, the vacuum system must be brought up to air prior to inserting a new sample. A vacuum interlock system was not designed into this prototype system for mechanical simplicity only and is planned for the future.

Crucible. A diagram of the crucibles used for this work is shown in Fig. 2. For isotope separator work, sample loading is usually of the order of tens of milligrams of material and the crucible shown in Fig. $2 \mathrm{~A}$ is used. This crucible consists of two tungsten metal components: the body with a large cavity opening for ease of sample loading and a cap with a $0.33 \mathrm{~mm}$ opening. For smaller samples ( $\ll 1 \mathrm{mg}$ typically used in mass spectrometry), the crucible shown in Fig. $2 \mathrm{~B}$ is used. This is a one-piece tungsten metal crucible with a $0.50 \mathrm{~mm}$ diameter and $1.25 \mathrm{~cm}$ deep cavity. In both cases, the ionizing channel opening presents a small apparent object to the ion optic system but is large enough to ensure that a quasi-neutral plasma can be maintained [25]. The crucible and its base plate can be electrically isolated and usually operates at about $40 \mathrm{~V}$ when used on the quadrupole mass spectrometer.

Filament and Shielding Can. The filament used in this work is made from two turns of $0.5 \mathrm{~mm}$ tantalum wire and is very similar to that reported in the literature [12]. The diameter of the filament's circular opening is usually set to about $12 \mathrm{~mm}$. The filament power supply floats at $-2500 \mathrm{~V}$ dc bias voltage, and can deliver up to $40 \mathrm{~mA}$ of electron emission current. For isotope separator work, ion acceleration is achieved by floating the complete ion source to $50,000 \mathrm{~V}$ dc. Although the power supply system for the isotope separator is capable of regulating the electron emission via computer control of the filament current and voltage, the power supply used for the quadrupole mass spectrometer had no emission regulation.

However, the filament current (and therefore emission current) can be manually controlled and has a stability of better than $5 \mathrm{~mA}$. Although this is adequate for the work presented in this report, a regulated emission power supply has been designed and is in construction for future 
work. While operation of the ion source for isotope separator applications using the large crucible shown in Fig. 2A can require 250-500 W of electron power for thorium operational temperatures to be reached, the smaller crucible (shown in Fig. 2B) reaches similar operating conditions with a maximum of $75 \mathrm{~W}$ of electron emission.

The shielding serves three functions. The first one is to shield other parts in the source from bombarding electrons and sputtered tungsten from the crucible. The second is to minimize the loss of heat produced in the electron bombarding process. The third is as the ion extractor for ions produced in the crucible since the shield is held at the electron bias voltage.

Cooling System. Cooling water channels have been designed into the system as shown in the axial view in Fig. 1B. Without cooling water flowing, the ion source body may reach temperatures that could damage adjoining equipment or personnel. A fan directing air onto the source body can also be used to provide sufficient cooling for the thin crucible shown in Fig. 2B.

\subsection{Mass Spectrometer and Isotope Separator}

The mass spectrometer used here is a compact system consisting of a one-stage pumping device, an electrostatic lens, a set of quadrupole magnets, and a commercially available detector. Vacuum pumping is performed with a mechanical pump at a rate of 330 $1 / \mathrm{min}$, which is sufficient to maintain a base pressure of $1 \times 10^{-8}$ Torr. The electrostatic lens, which consists of three cylindrical plates, is used to focus the ion beam that escapes from the crucible tip into the quadrupole. The dimensions of the plates are $7.0 \mathrm{~cm}$ o.d., $0.55 \mathrm{~cm}$ i.d. (first plate), and $0.25 \mathrm{~cm}$ i.d. (second and third plates). The distances between the plates are $1.17 \mathrm{~cm}$ (first and second plates) and $0.51 \mathrm{~cm}$ (second and third plates). The plates are isolated from each other by using ceramic material. Negative voltages are applied to the lens to extract the ion beam and to reduce the electrons. A computer-based data acquisition and control system is used for operating the instrument. The typical experimental parameters used for the quadrupole system are given in Table 1.

The isotope separator used in this work for ionization efficiency measurements is a laboratory-built room-size instrument, which is routinely used for isotope separation and research. The ion transmission efficiency in the separator is over $99 \%$, which assures good performance for the ionization efficiency measurement. An externally controlled Faraday cup assembly can be attached in front of the collection system, and was used to measure the total ion current produced by the source.

\subsection{Sample Preparation and Running}

Powder samples in oxide form are almost exclusively employed in this work. Some rare earth elements and actinides are typically used to examine the source performance. The samples are packed into the tube by pressing the tube into a small container filled with the 
sample powder. A clean tungsten wire is usually used to make sure the samples are at the bottom of the crucible channel and tight. The packed crucible is then mounted on the crucible holder and inserted into the source. The alignment of the crucible can be facilitated by adjusting the screws in the crucible holder to obtain the optimum beam intensity. Each crucible is degassed in the source at lower temperature to remove any volatile contaminants until the vacuum pressure is lower than $1 \times 10^{-6}$ Torr. The temperature is then increased in steps, and signals from both background and analytes are monitored.

\section{4. Results and Discussion}

Behavior of Background and Analyte Elements. Using the above procedure, the background contribution from the tungsten crucible itself is examined before loading samples. After removing the volatile species in the vacuum system by baking the filament at a certain current, the bombardment voltage is slowly increased to produce a beam intensity. Background peaks from potassium (at masses of 39 and 41) and sodium (mass 23) were observed at electron emission currents of 2-4 mA (see Fig. 3a and 3b). The ion current of these impurities is over $10^{-10} \mathrm{~A}$. Usually the potassium peaks appear first at relatively lower emission current (about $2 \mathrm{~mA}$ ) and last a relatively longer time (several hours), while the sodium peak needs a little higher emission current (over $3.2 \mathrm{~mA}$ ) to reach its maximum value and soon diminishes depending on the voltage and the current used. At this current level, no signals from the sample were observed in the follow-on experiments. With the increasing of the emission current, both potassium and sodium signals disappeared when the current was more than 4-5 $\mathrm{mA}$. Therefore, these background peaks do not influence the measurement of sample elements, even though they may have peaks at the same mass numbers.

A mixed sample of rare earth elements europium, samarium and lutetium with a ratio of 1:1:1 was used for testing. The sample amount used in this experiment was about 1 milligram. The selection of elements is based on the first-ionization potential of the elements and their vapor pressure, which are considered as the two most important factors in the performance of thermal ionization sources. As indicated in Table 2, these three rare earth elements have similar

first-ionization potential but quite different temperature for achieving $10^{-4}$ Torr vapor pressure, which leads to different behaviors in the source. Figures 4-6 show some results for the rare earth elements selected. When the bias voltage was kept constant at $2500 \mathrm{~V}$, increasing electron emission current means increasing input power or temperature.

For this mixed sample, the europium signals can be obtained at an emission current of about $20 \mathrm{~mA}$. As is shown in Fig. 4, no signals can be observed for other sample elements at this current level. The background examination at mass numbers of 39 and 23 again shows that no impurities from potassium or sodium exist at this emission current level. Further increasing the current up to about $23 \mathrm{~mA}$ results in samarium peaks as shown in Fig. 5 . In this 
case, only a very small peak for lutetium at mass number 175 can be observed. The large peaks for lutetium in Fig. 6 are obtained by using an emission current of about $27 \mathrm{~mA}$. At this current, the europium was soon evaporated and the peaks diminish as shown in the figure.

Fig. 7 shows uranium signals obtained from uranium oxide samples. The emission current used to obtain these signals is about $32 \mathrm{~mA}$. The oxide peaks that appear at 254 (for $238 \mathrm{U}$ ) and 251 (for 235U) are much larger than their corresponding metal signals. This means that measures should be taken in future research to cut down oxide peaks and to enhance the metal peaks.

Isotope Ratio Measurements. Because of its high precision and accuracy, one important application of the thermal ionization technique is to measure element isotope composition and isotope ratio. To evaluate the new source developed in this work, and also to demonstrate the performance of the source coupled to the quadrupole system, isotope ratio measurements have been carried out with some typical rare earth elements such as europium and samarium. The isotope peaks at 144, 147, 148, 149, 150, 152 and 154 for samarium were simultaneously measured and the relative ratios calculated. As is shown in Fig. 8 for fifty continuous collections, very good performance has been obtained with this new source and the quadrupole system.

Table 3 gives the detailed information for the isotope ratio measurements of europium and samarium. The internal precision given in the table is obtained in a short time period (about $10 \mathrm{~min}$ ) and is based on the calculation of fifty continuous measurements. Although the precision varies with isotope and its abundance, a typical precision of better than $0.1 \%$ can be readily attained by this new source with the quadrupole system. Some measurements with precision as high as tens of ppm can also be attained. This precision is comparable to, or even better than, the values obtained by the magnetic sector or isotope separator systems [28-31]. These competitive results reveal the potential applications of the new source with the simple quadrupole system.

Ionization Efficiency Measurements. The ionization of analytes in a hot cavity originates from surface ionization at the walls of the cavity. The ionization efficiency can be described by the Langmuir expression, which is given in reference [33]. Table 2 indicates the elements for which the thermal ionization source is suitable. As was described by several authors [14, 25-27], the ionization efficiency for a certain element is strongly dependent on its first ionization potential (through the Saha-Langmuir equation) and the operating temperature (through the vapor pressure of contaminants). In addition, the ionization efficiency seems also correlated with the ionizer's material and geometry [27] as well as operating time [34].

In our work, we have tested a series of rare earth and actinide elements to measure the ionization efficiency by using the new cavity. The results are presented in Table 4, which 
shows that an ionization efficiency up to $72 \%$ can be obtained. We found that outgassing of the system and crucible baking are very important for achieving better performance. For example, using a pre-baked tungsten crucible, which had been baked to a temperature where thorium could be seen as a contaminant of the tungsten, we achieved europium ionization efficiency of $72 \%$. However, if we used an unbaked crucible, $40 \%$ efficiencies were the norm. These results reflect the values reported in reference [12]. Lutetium has a slightly lower first ionization potential but twice the vaporization temperature of europium. These differences cause increased vaporization of contaminants including tungsten itself, and lead to lower efficiences of about $25 \%$. Zirconium is an element having both high ionization potential and low vapor pressure. The ionization efficiency measured for it ranges from $2 \%$ to $3 \%$. These results again demonstrate that both elemental ionization potential and vapor pressure have an important influence on the ionization efficiency.

Possible Mechanism for Efficiency Improvement. In a conventional thermal ionization source, such as ribbon-type, the sample to be analyzed is placed on a thin, flatribbon filament, which is heated by passing a current through the filament, much like the filament in a light bulb. The filament is heated to temperatures of up to $2500^{\circ} \mathrm{C}$ [8], and sample atoms are evaporated from the surface of the filament. Ionization occurs as a result of the interaction between a gaseous sample atom and the filament surface in which an electron from the sample atom is passed onto the hot metal surface to produce a positive ion of the sample. Because the filament must be placed in a high vacuum, the atoms evaporated from the filament have limited contact with the filament surface. In fact, once the atoms leave the immediate region near the filament surface, they are not likely to interact with the filament surface again. Therefore, the ionization efficiency for the filament-type source is very low.

In our new thermal ionization source, the sample is placed deep inside a small tungsten crucible, which is held and centered in the miniature cavity. The crucible is then heated by bombardment from electrons emitted from the metal filament located around the crucible. As the sample evaporates inside the crucible, the pressure inside the crucible increases, and the gaseous atoms produced interact with each other and with the inner wall of the crucible to produce positive ions of the analytes. Because of the very limited space inside the cavity and relatively large surface, the interactions between the atom and the surface are considerably increased compared with filament-type cavities. According to Kirchner [27], for a tungsten cylinder with $0.2 \mathrm{~cm}^{3}$ volume and an orifice of $0.7 \mathrm{~mm}$ in diameter operated at a temperature of about $2850 \mathrm{~K}$, the atoms make about 700 collisions with the wall before escaping through the exit hole. This partially explains the high efficiency obtained with the new cavity. Another reason for efficiency improvement is the higher operational temperature used in this new cavity. With the energy deposited on the crucible, the temperature of the tube-type cavity can 
reach up to $3000^{\circ} \mathrm{C}$ or even higher [12]. The thickness of the crucible and better shielding allow it to easily survive at such a temperature, which the filament-type cavity can not bear.

\section{References}

[1] H. G. Thode, C. C. McMullen and K. Fritze, "Advances in Inorganic Chemistry and Radiochemistry", Vol. 2, Academic, New York, 1960, pp. 315-362.

[2] L. F. Herzog, Int. J. Mass Spectrom. Ion Phys, 4, 253 (1970).

[3] P. J. Pauisen and W. R. Kelly, Anal. Chem., 56, 708 (1984).

[4] S. K. Aggarwal, R. K. Duggal, P. M. Shah and H. C. Jain, Int. J. Mass Spectrom. Ion Processes, 85, 137 (1988).

[5] R. F. Cretella, R. A. Lukaszew, J. G. Marrero and R. Servant, Int. J. Mass Spectrom. Ion Processes, 98, 99 (1990).

[6] D. Poupard and A. Juery, Radiochimica Acta, 57, 21 (1992).

[7] A. S. Cohen and R. K. O'Nions, Anal. Chem.,63, 2705 (1991).

[8] A. M. Volpe, J. A. Olivares and M. T. Murrell, Anal. Chem., 63, 913 (1991).

[9] A. G. Adriaens, J. D. Fassett, W. R. Kelly, D. S. Simons and F. C. Adams, Anal. Chem., 64, 2945 (1992).

[10] J. A. Mchugh, Int. J. Mass Spectrom. Ion Phys, 3, 267 (1969).

[11] G. J. Beyer, E. Herrmann, A. Piotrowski, V. J. Raiko and H. Tyrroff, Nucl. Instr. and Meth., 96, 437 (1971).

[12] P. G. Johnson, A. Bolson and C. M. Henderson, Nucl. Instr. and Meth., 106, 83 (1973).

[13] V. A. Karnaukhov, D. D. Bogdanov, A. V. Demyanov, G. I. Koval and L. A. Petrov, Nucl. Instr. and Meth., 120, 69 (1974).

[14] A. Latuszynski and V. I. Raiko, Nucl. Instr. and Meth., 125, 61 (1975).

[15] S. Amiel, G. Engler, Y. Nir-el and M. Shmid, Nucl. Instr. and Meth., 139, 305 (1976).

[16] M. Shmid, Y. Nir-el, G. Engler and S. Amiel, Nucl. Instr. and Meth., 144, 601 (1977).

[17] J. Munzel, H. Wollnik, B. Pfeiffer and G. Jung, Nucl. Instr. and Meth., 186, 343 (1981).

[18] E. H. Spejewski, Nucl. Instr. and Meth., 186, 317 (1981).

[19] A. Piotrowski, R. L. Gill and D. C. McDonald, Nucl. Instr. and Meth., 224, 1 (1984).

[20] E. H. Pilzer and G. Engler, Nucl. Instr. and Meth., B26, 218 (1987).

[21] J. E. Delmore, A. D. Appelhans and E. S. Peterson, Int. J. Mass Spectrom. Ion Processes, 108, 179 (1991).

[22] R. Kirchner, Nucl. Instr. and Meth., 186, 275 (1981). 
[23] W. K. Huber and G. Rettinghaus, 1638.

[24] V. P. Afanas'ev, V. A. Obukhov and V. I. Raiko, Nucl. Instr. and Meth., 145, 533 (1977).

[25] R. Kirchner and A. Piotrowski, Nucl. Instr. and Meth., 153, 291 (1978).

[26] M. Huyse, Nucl. Instr. and Meth., 215, 1 (1983).

[27] R. Kirchner, Nucl. Instr. and Meth., A292, 203 (1990).

[28] Y. K. Xiao, E. S. Beary and J. D. Fassett, Int. J. Mass Spectrom. Ion Processes, 85, 203 (1988).

[29] J. Volkening, M. Koppe and K. G. Heumann, Int. J. Mass Spectrom. Ion Processes, 107, 361 (1991).

[30] R. A. Creaser, D. A. Papanastassiou and G. J. Wasserburg, Geochim. Cosmochim. Acta., 55, 391 (1991).

[31] T. Walczyk and K. G. Heumann, Int. J. Mass Spectrom. Ion Processes, 123, 139 (1993).

[32] I. Langmuir and K. H. Kingdom, Proc. Roy. Soc. London, 107, 61 (1925).

[33] G. J. Beyer, E. Herrmann, F. Molnar, V. I. Raiko and H. Tyrroff, Radiochem. Radioanal. Letters, 12, 259 (1972).

[34] A. Zindler, J. L. Rubenstone, J. England, B. Bourdon, L. Reisberg, B. Hamelin, V. Salters, S. Weaver, W.-X. Li, and F. Marcantonio, "SIMS measurements of $230 \mathrm{Th} / 232 \mathrm{Th}$ ratios in rocks" in International Conference on Geochronology, Cosmochronology, and Isotope Geology, Canberra Australia, September 24-29, 1990.

\section{DISCLAIMER}

This report was prepared as an account of work sponsored by an agency of the United States Government. Neither the United States Government nor any agency thereof, nor any of their employees, makes any warranty, express or implied, or assumes any legal liability or responsibility for the accuracy, completeness, or usefulness of any information, apparatus, product, or process disclosed, or represents that its use would not infringe privately owned rights. Reference herein to any specific commercial product, process, or service by trade name, trademark, manufacturer, or otherwise does not necessarily constitute or imply its endorsement, recommendation, or favoring by the United States Government or any agency thereof. The views and opinions of authors expressed herein do not necessarily state or reflect those of the United States Government or any agency thereof. 
Table 1. Experimental and Operating Conditions for TIMS.

Parameter

Vacuum pressure (mbar)

Extraction voltage (first ion lens)(V)

Second ion lens (V)

Ion accelerating voltage $(\mathrm{V})$

Bias voltage $(\mathrm{V} \mathrm{dc})$

Filament current (A)

Sample loading amount

Emission current used (mA)

REE

$\mathrm{U}$

Th

$\mathrm{K}$ and $\mathrm{Na}$

Crucible size

Depth (cm)

Diameter $(\mathrm{cm})$ $\underline{\text { Value }}$

$\sim 5 \times 10^{-8}-5 \times 10^{-7}$

$\sim 70$

$\sim 240$

$\sim 54$

$\sim 2500$

$\sim 8.0$ - 9.8

$\sim \mathrm{mg}$

$\sim 20-28$

$-30-32$

$\sim 37-40$

$-2-4$

$\sim 1.27$

$\sim 0.159$ 
Table 2. First ionization potential (IP) for selected elements and temperature to reach $10^{-4}$ Torr pressure.

\begin{tabular}{|c|c|c|}
\hline Element & $\underline{\mathrm{IP}}(\mathrm{eV})$ & Temperature (K) \\
\hline $\mathrm{Li}$ & $\overline{5.4}$ & 670 \\
\hline $\mathrm{Na}$ & 5.1 & 465 \\
\hline $\mathrm{K}$ & 4.3 & 395 \\
\hline $\mathrm{Rb}$ & 4.2 & 365 \\
\hline Cs & 3.9 & 350 \\
\hline $\mathrm{Mg}$ & 7.6 & 600 \\
\hline $\mathrm{Ca}$ & 6.1 & 730 \\
\hline $\mathrm{Sr}$ & 5.7 & 680 \\
\hline $\mathrm{Ba}$ & 5.2 & 730 \\
\hline $\mathrm{Ra}$ & 5.3 & 690 \\
\hline $\mathrm{Sc}$ & 6.6 & 1375 \\
\hline $\mathrm{Y}$ & 6.4 & 1600 \\
\hline $\mathrm{La}$ & 5.8 & 1700 \\
\hline $\mathrm{Ti}$ & 6.8 & 1710 \\
\hline $\mathrm{Zr}$ & 6.8 & 2275 \\
\hline$\overline{\mathrm{Hf}}$ & 6.8 & 2275 \\
\hline$\vec{V}$ & 6.7 & 1820 \\
\hline $\mathrm{Cr}$ & 6.8 & 1430 \\
\hline $\mathrm{Mn}$ & 7.4 & 1020 \\
\hline $\mathrm{Fe}$ & 7.9 & 1500 \\
\hline $\mathrm{Co}$ & 7.9 & 1530 \\
\hline $\mathrm{Ni}$ & 7.6 & 1530 \\
\hline $\mathrm{Cu}$ & 7.7 & 1300 \\
\hline $\mathrm{Tc}$ & 7.3 & 2350 \\
\hline $\mathrm{Ru}$ & 7.4 & 2250 \\
\hline $\mathrm{Rh}$ & 7.5 & 1975 \\
\hline $\mathrm{Ag}$ & 7.6 & 1100 \\
\hline $\mathrm{Al}$ & 6.0 & 1250 \\
\hline $\mathrm{Ga}$ & 6.0 & 1175 \\
\hline In & 5.8 & 1000 \\
\hline $\mathrm{Tl}$ & 6.1 & 740 \\
\hline $\mathrm{Ce}$ & 5.5 & 1650 \\
\hline $\mathrm{Pr}$ & 5.5 & 1420 \\
\hline Nd & 5.5 & 1325 \\
\hline $\mathrm{Pm}$ & 5.6 & 1050 \\
\hline $\mathrm{Sm}$ & 5.6 & 850 \\
\hline $\mathrm{Eu}$ & 5.7 & 730 \\
\hline $\mathrm{Gd}$ & 6.2 & 1350 \\
\hline $\mathrm{Tb}$ & 5.8 & 1425 \\
\hline Dy & 5.9 & 1125 \\
\hline Ho & 6.0 & 1225 \\
\hline $\mathrm{Er}$ & 6.1 & 1225 \\
\hline $\operatorname{Tm}$ & 6.2 & 950 \\
\hline $\mathrm{Yb}$ & 6.3 & 690 \\
\hline $\mathrm{Lu}$ & 5.4 & 1550 \\
\hline $\mathrm{Th}$ & 6.1 & 2250 \\
\hline $\mathrm{U}$ & 6.2 & 1850 \\
\hline $\mathrm{Pu}$ & 6.1 & 1475 \\
\hline $\mathrm{Am}$ & 6.0 & 1130 \\
\hline
\end{tabular}


Table 3. Isotope ratio measurements and precision.

$\begin{array}{lllll}\text { Element } & \text { Ratio } & \begin{array}{l}\text { Average } \\ \text { Value }\end{array} & \begin{array}{l}\text { Standard } \\ \text { Deviation }\end{array} & \text { RSD (\%) } \\ & & & & \\ \mathrm{Eu} & 151 / 153 & 0.9862 & 0.000034 & 0.0034 \\ \mathrm{Sm} & 144 / 152 & 0.1750 & 0.000127 & 0.073 \\ & 147 / 152 & 0.6653 & 0.00140 & 0.21 \\ & 148 / 152 & 0.4995 & 0.000891 & 0.18 \\ & 149 / 152 & 0.5852 & 0.000923 & 0.16 \\ & 150 / 152 & 0.3233 & 0.000395 & 0.12 \\ & 154 / 152 & 0.8128 & 0.000145 & 0.018\end{array}$

Table 4. Ionization efficiency measured with present source.

$\begin{array}{llc}\text { Element } & \text { Form } & \text { Efficiency } \\ \mathrm{Eu} & \mathrm{Eu2O3} & 72 \% \\ \mathrm{Lu} & \mathrm{Lu2O3} & 25 \% \\ \mathrm{U} & \mathrm{U} 3 \mathrm{O} 8 & 8 \% \\ \mathrm{Th} & \mathrm{ThO} 2 & 2 \% \\ \mathrm{Zr} & \mathrm{ZrO} 2 & 2 \%\end{array}$




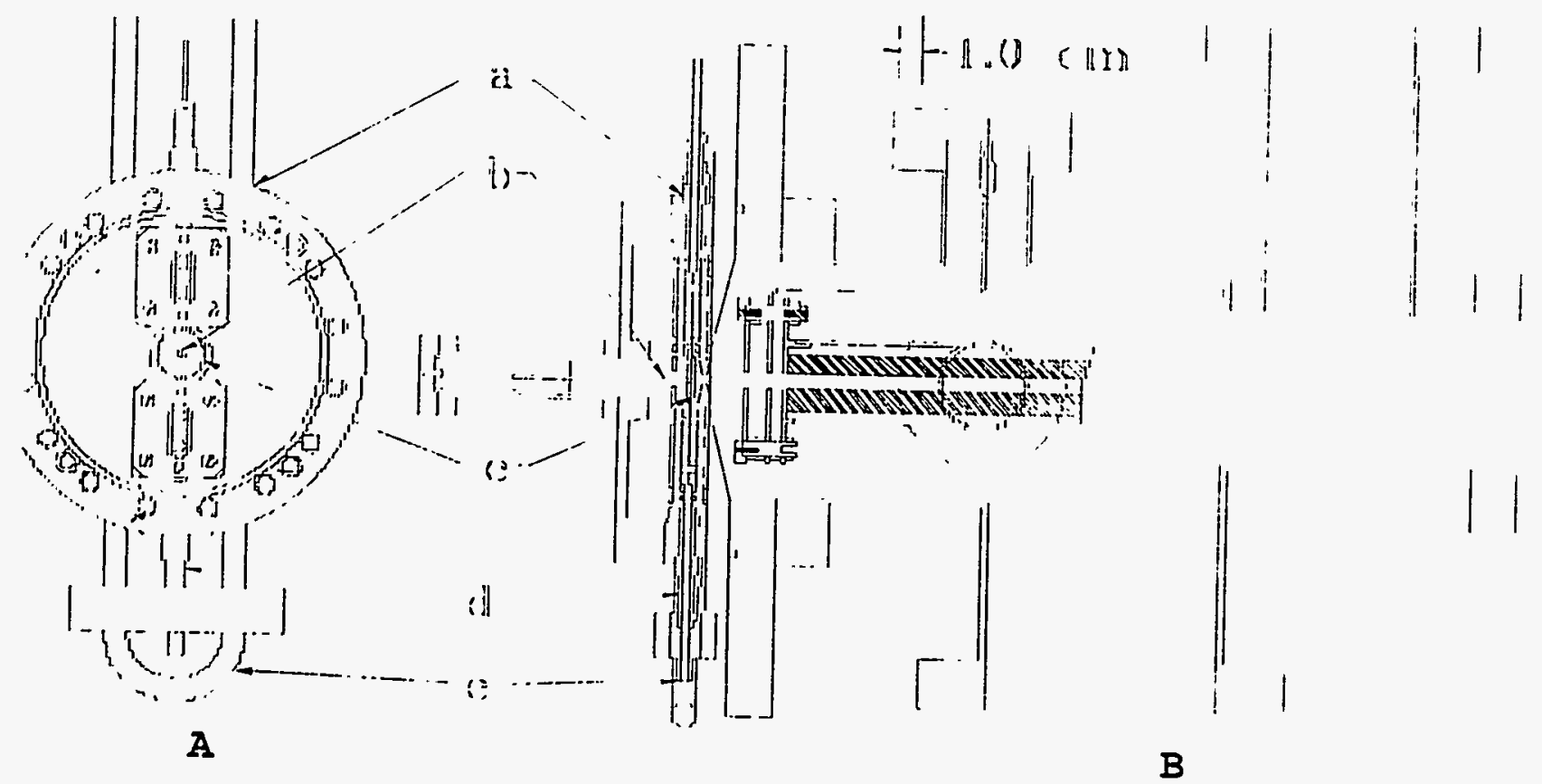

Fig. 1. Schematic diagram of the new ion source and its coupling with a simple quadrupole system. (A) coaxial view of the source, (B) ion source mounted on a quadrupole mass spectrometer, a) source flange, b) cavity, c) shielding can, d) electrical feedthroughs, and e) water cooling. 
(a)
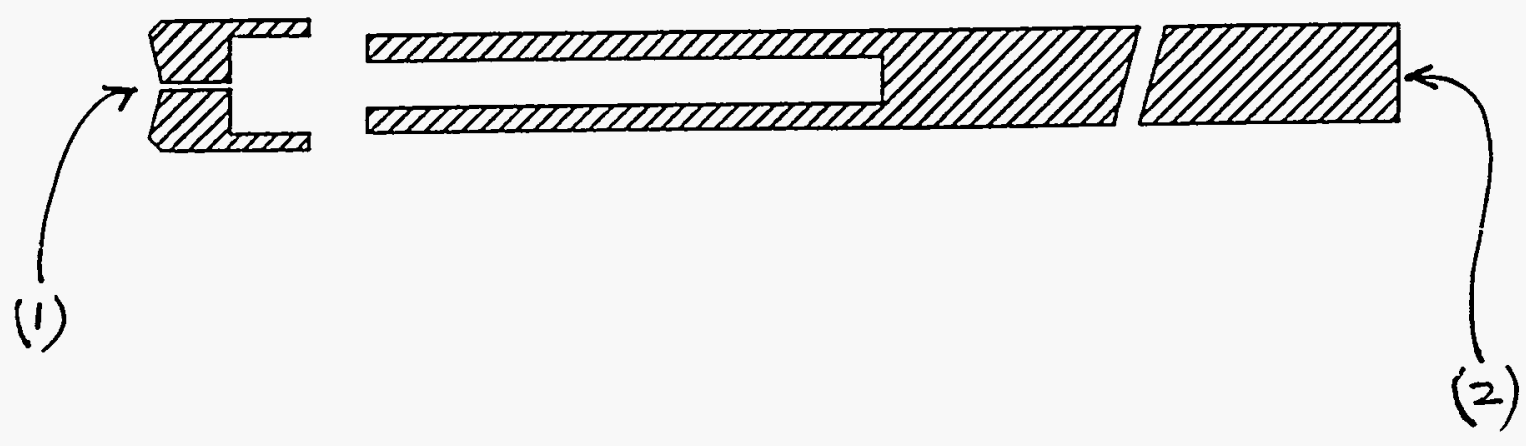

(b)

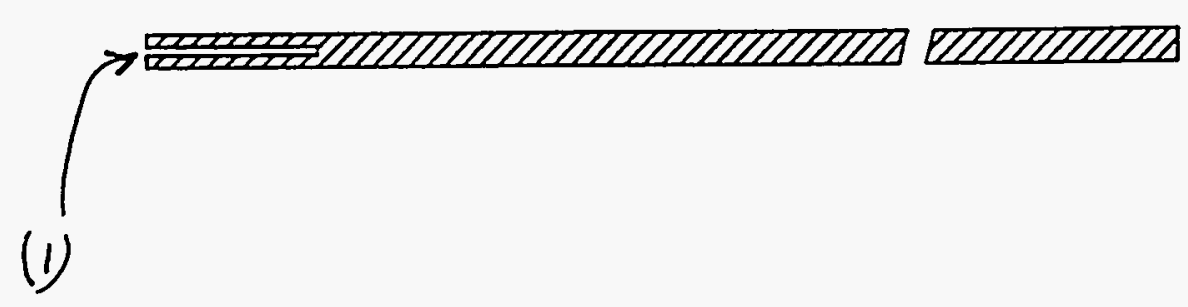

Fig. 2. Tungsten crucibles used for thermal ionization source. (a) crucible for isotope separator, (b) crucible for quadrupole mass spectrometer, 1) ionization channel, and 2) crucible cap. 


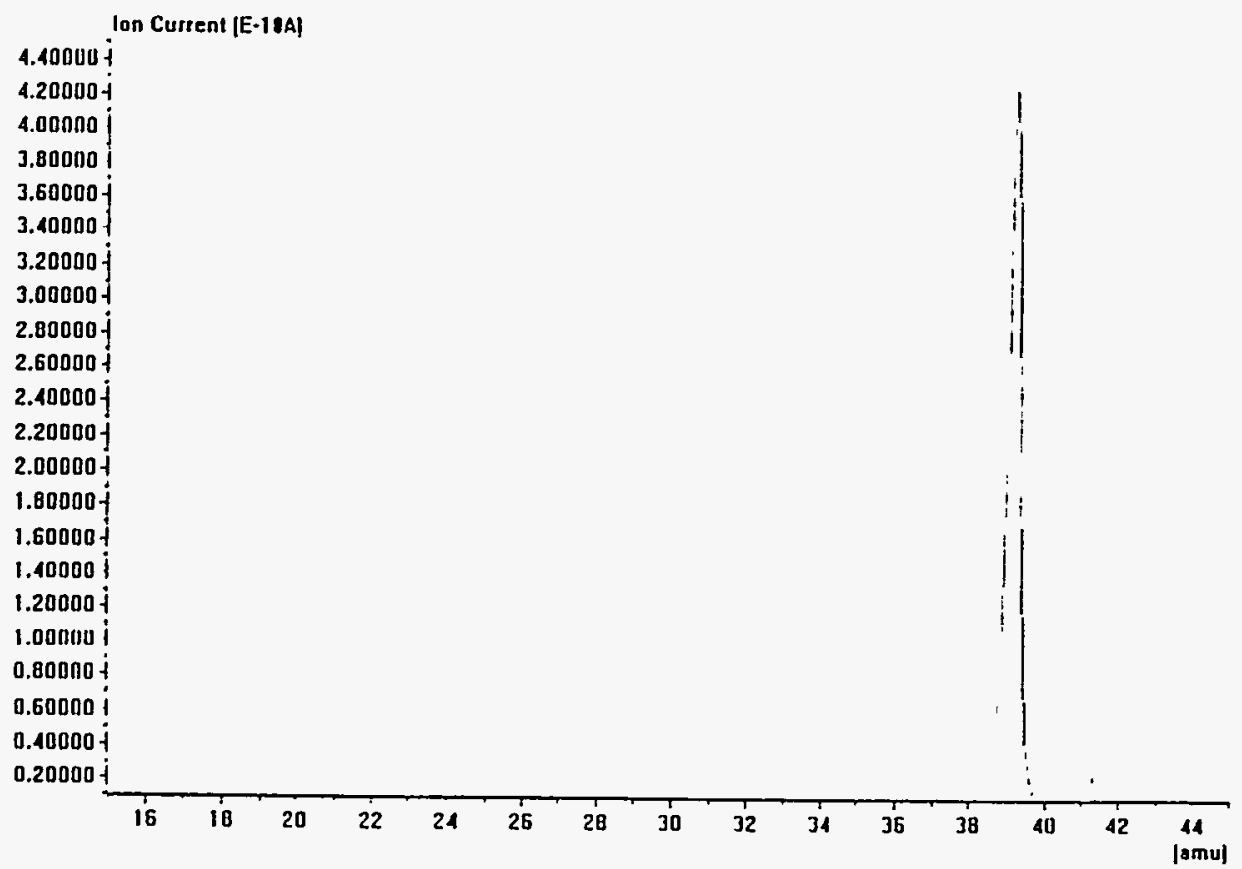

(A)

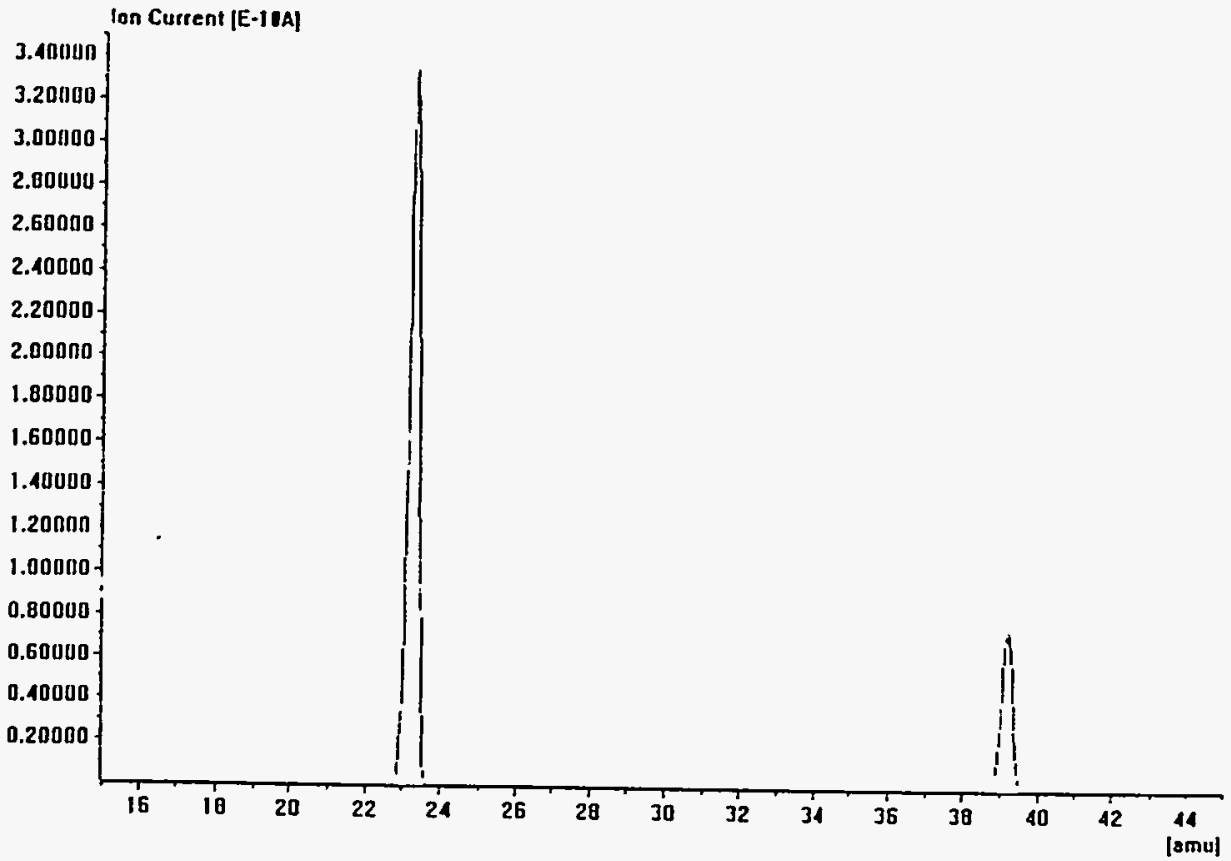

(B)

Fig. 3. Background peaks observed in the crucible source. (A) background peaks of potassium obtained at an emission current of about $2 \mathrm{~mA}$ and (B) background peaks of sodium obtained at an emission current of about $3.5 \mathrm{~mA}$. Other experimental conditions are as shown in Table 1. 


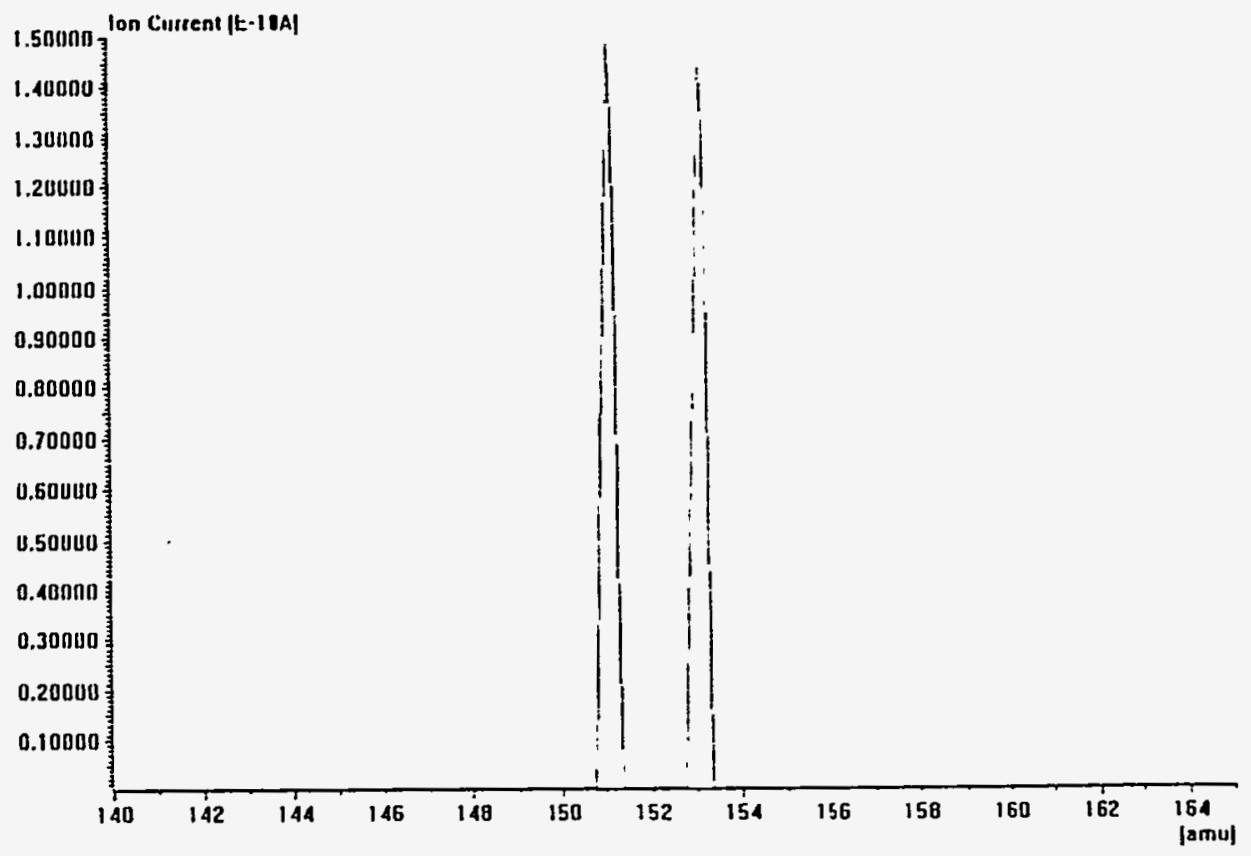

Fig. 4. Isotope peaks of europium obtained at an emission current of about $20 \mathrm{~mA}$. Other experimental conditions are as shown in Table 1.

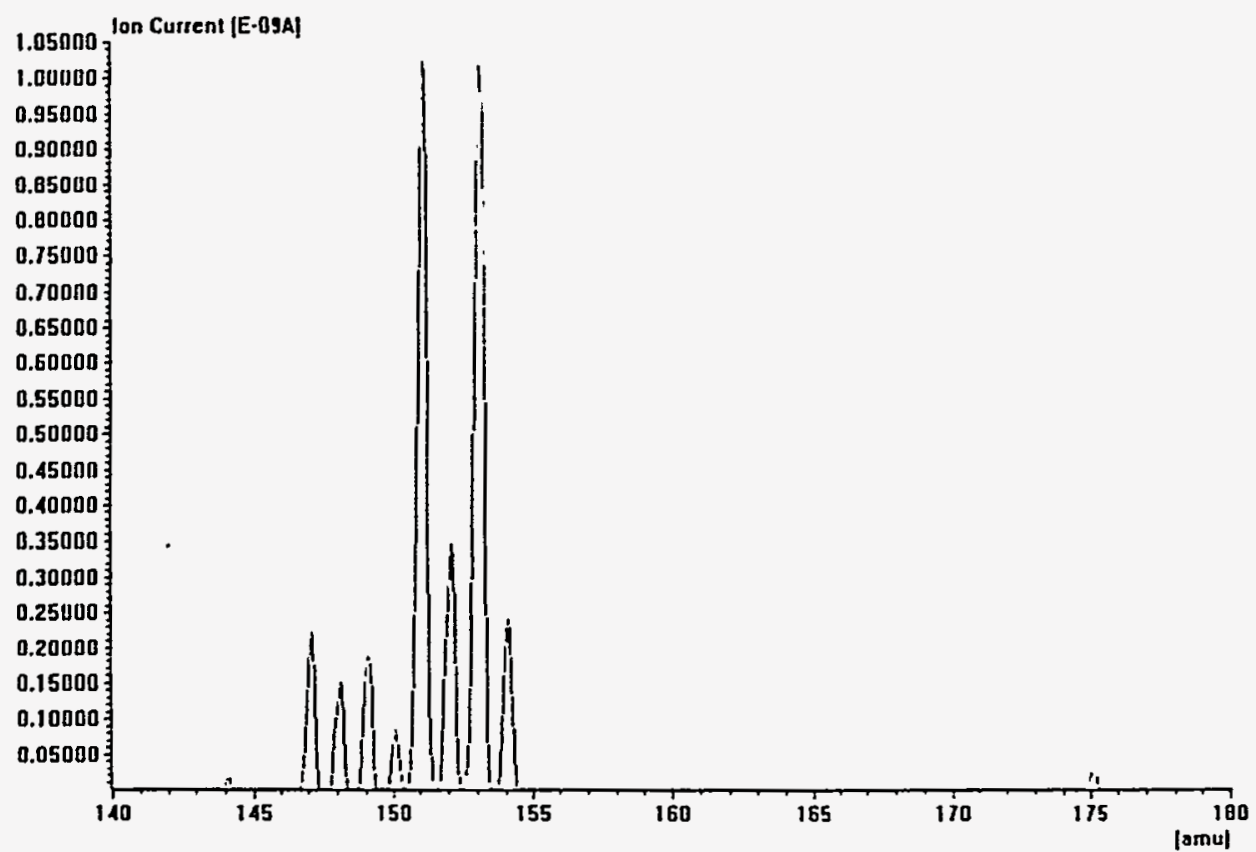

Fig. 5. Isotope peaks of europium and samarium obtained at an emission current of about $23 \mathrm{~mA}$. Other conditions are the same as in Fig. 4. 


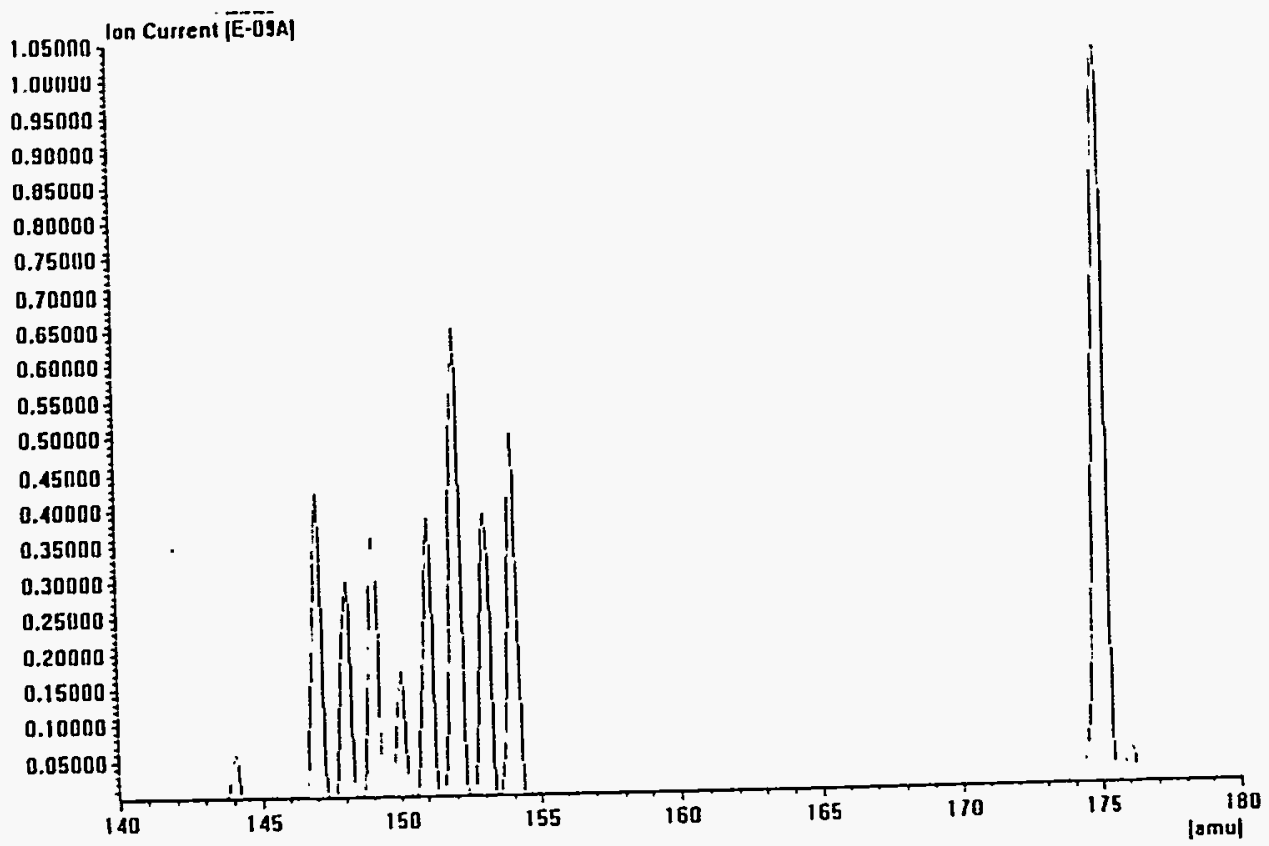

Fig. 6. Isotope peaks of europium, samarium and lutetium. The peaks are obtained at an emission current of about $27 \mathrm{~mA}$. Other experimental conditions are the same as in Fig. 4.

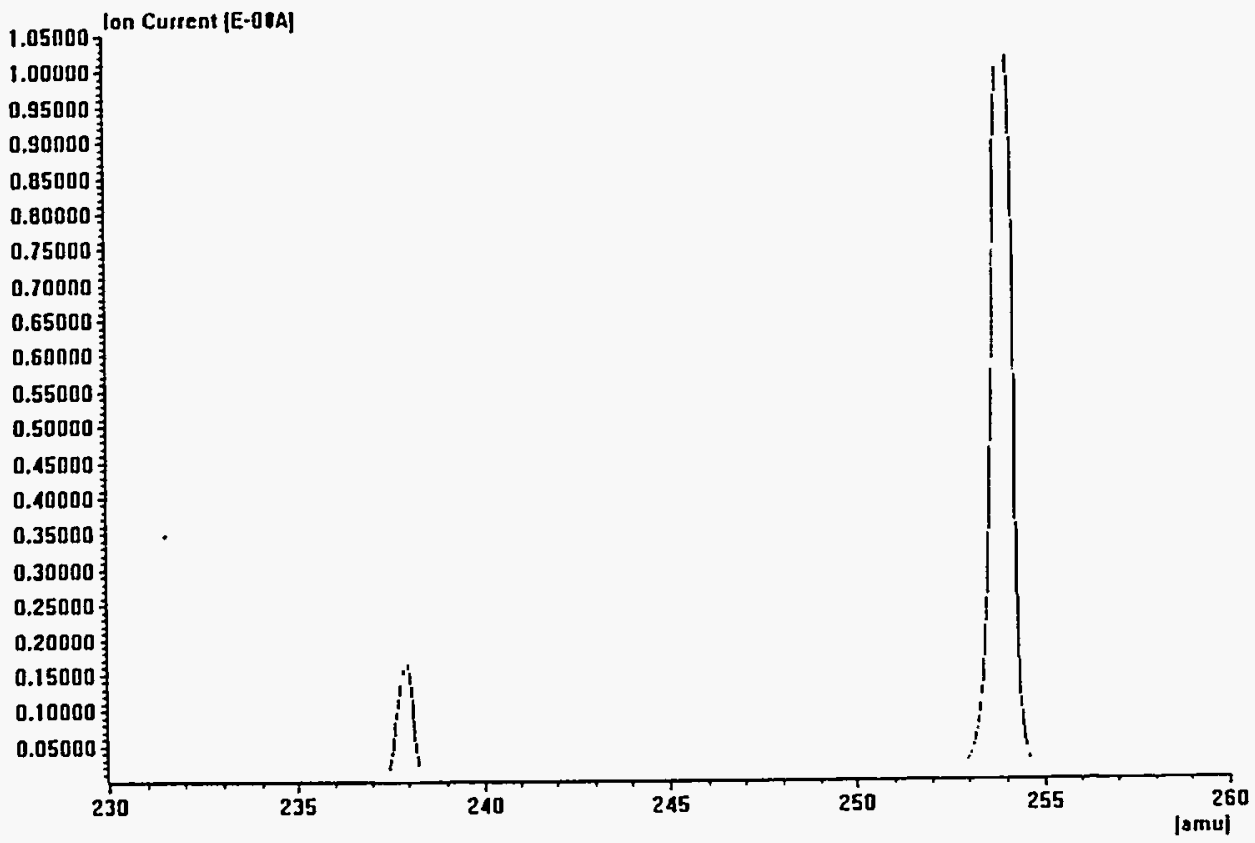

Fig. 7. Uranium isotope peaks obtained with uranium oxide at an emission current of about $30 \mathrm{~mA}$. 


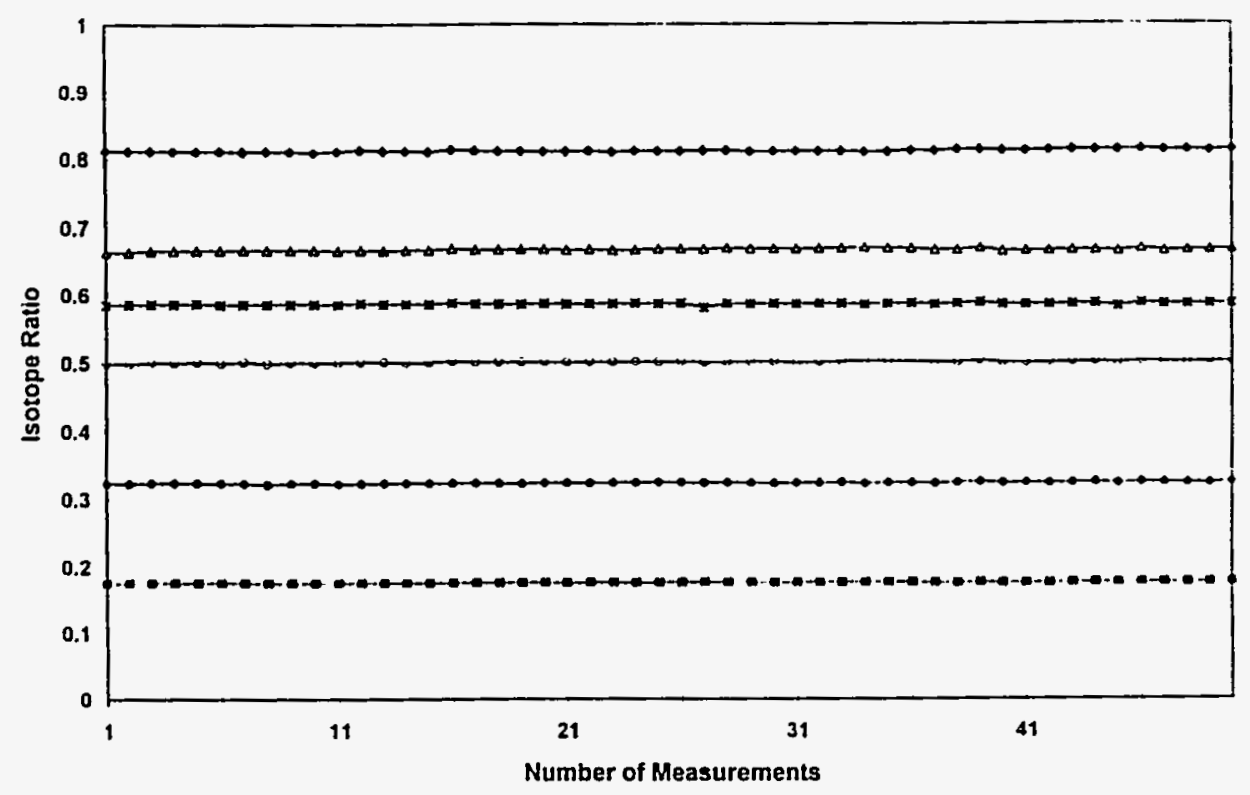

Fig. 8. Samarium isotope ratio plot. All peaks were monitored and collected simultaneously in a short time period. Background correction and mass discrimination correction were not made for the calculation of the isotope ratios. 